\title{
Uma Organização Religiosa pensada a partir da Teoria das Estruturas Organizacionais em Mintzberg
}

\author{
Bertha Maria do Amaral e SILVA
}

Universidade Federal de Pernambuco (UFPE), Caruaru, PE, Brasil

Ítalo Henrique F. R. da SILVA

Universidade Federal de Pernambuco (UFPE), Caruaru, PE, Brasil

\author{
Bruno Gustavo Ferreira do NASCIMENTO \\ Universidade Federal de Pernambuco (UFPE), Caruaru, PE, Brasil
}

Elisabeth Cavalcante dos SANTOS

Universidade Federal de Pernambuco (UFPE), Caruaru, PE, Brasil

\author{
Received30dez. 18;Accepted22jan. 19 \\ Evaluation System: Guest Article (Best paper of the 1st Scientific Conference on Administration [JCA] - UFPE / CAA) \\ Editor: Jose Lindenberg Julião Xavier Filho, Dr.
}

ISSN: 2594-8040

To cite thispaper: Silva, B. M. A., Silva, I. H. F. R., Nascimento, B. G. F., \& Santos, E. C. (2018). Uma organização religiosa pensada a partir da Teoria das Estruturas Organizacionais em Mintzberg. Journal of Perspectives in Management - JPM, 2(2), p. 18-33.

\section{Resumo}

Neste estudo o objetivo foi pensar a teoria das estruturas organizacionais em Mintzberg $(1981,2003)$ a partir de uma organização religiosa. Uma vez que estas organizações apresentam características peculiares enquanto sua institucionalização no âmbito social, político e cultural nas comunidades em que se fazem presentes, organizadas através do trabalho voluntário, solidariedade e crenças dogmáticas. Assim, para compreendermos a estrutural organizacional e suas características, foi realizada uma pesquisa qualitativa, por meio de entrevistas com diversas lideranças organizacionais, incluído figura do líder principal da organização. Conseguimos perceber uma estrutura organizacional com foco na burocracia mecanizada, composta por três partes organizacionais distintas coordenadas principalmente por meio do ajustamento mútuo.

Palavras-Chave: Estrutura Organizacional, Igreja Católica, Mintzberg. 


\section{Introdução}

O debate acadêmico sobre as teorias das estruturas organizacionais é extenso, sobretudo em se tratando de organizações de caráter empresarial. Muito porque, ao longo do tempo, os estudos em administração se voltaram a analisar, teórico e empiricamente, as estruturas empresariais com enfoque na definição de objetivos quantitativos, de adaptabilidade organizacional, racionalidade de recursos, integração e coordenação de diferentes unidades produtivas (Schultz, 2016), com o intuito permanente de alavancar a eficiência e eficácia dos meios produtivos.

Recentemente, entretanto, observamos o desenvolvimento de pesquisas em diversos temas da administração em organizações de caráter religioso como alternativa aos estudos convencionais. Temas como: a empresarização do sagrado (Gonçalves, Serra\& Costa, 2007), a análise das relações entre as organizações religiosas e seus stakeholders (Serafim\&Alperstedt, 2012) e as relações interpessoais na administração de pessoas a partir dos eclesiásticos (Lima, 2016). Essas pesquisas apontam para a importância de estudar os diferentes tipos de organizações retratando suas estruturas, seus mecanismos de gestão, seus sistemas de planejamento e controle e seus agrupamentos funcionais.

A entender que as organizações religiosas apresentam forte influência nas sociedades em que atuam, são diversificadas, e apresentam estruturas organizacionais variadas que lhes dão formas. Chamamos a atenção aqui para o arranjo de ordenação interna da Igreja Católica respaldada na rigidez, densa e uniforme, que guarda ainda níveis elevados de obediência e de autoridade. No entanto, percebemos também que a organização em questão apresenta forte demanda nas prestações de serviços em prol da fé, possuindo forte participação popular engajada em crenças místicas que promovem os eventos, as festas e os rituais simbólicos e religiosos, fazendo-os perdurarem no tempo.

Com isto, é possível notar a influência que as organizações religiosas, especificamente as de natureza católica, possuíram/possuem na sociedade brasileira como uma organização que opera históricos, social e culturalmente. Sua estrutura organizacional secular resistiu/resiste sempre configurando padrões de ação humana, evangelização e caracterização da moral cristã em comunidade (Woods Jr., 2008). Compreendemos, portanto, que a religião e por consequência as organizações religiosas, tem papel central nas sociedades ocidentais, sobretudo as organizações católicas, que no decorrer do tempo, foram transformando-se e definindo sua identidade com forte apoio popular que legitima rígidos sistemas organizacionais de controle, mando fé e dogmas.

Acreditamos que essa doutrina cristã sempre esteve amparada por uma estrutura organizacional que também é a uma estrutura social construída na coletividade (Compêndio, 2005; Nicolini, 2012). Sendo assim, mais do que revisitar a teoria tipológica das estruturas organizacionais de Mintzberg (1981, 2003), buscamos nessa pesquisa entendê-las a parti de uma organização religiosa de natureza católica no interior do Estado de Pernambuco. Desse modo, partimos do pressuposto que não podemos supor que as pesquisas constantemente realizadas para entender as estruturas organizacionais das instituições empresariais sirvam de modo genérico, para entender as estruturas organizacionais das instituições religiosas por alguns motivos.

Primeiro, porque as organizações apresentam uma natureza-fim de atuação diferente, a priori. Uma vez que as organizações de natureza empresarial atendem a fins de maximização de ganho monetário, em contraponto, as organizações de natureza religiosa objetivam disseminação da ideológica da fé, propagando o projeto de evangelização em consonância com uma visão "cristianizada" da ordem social e manutenção da presença matriz da religião na organização social (Cardim, 2001; Compêndio, 2005; CNBB, 2008).

Segundo, porque a natureza das relações de trabalho diverge. Essencialmente, as organizações empresariais apresentam uma estrutura de trabalho pautado no assalariamento, na troca monetária pela força de trabalho provenientes dos seus funcionários. Já as organizações de natureza religiosa, em especial a Igreja Católica foco desse estudo, apresentam uma estrutura de trabalho baseado na voluntariedade.

Com isto, os sujeitos se engajam nas atividades religiosas organizacionais por conta própria, livre de salários, mas carregados de subjetividade com sentimentos de fé na "alegria de ser um discípulo missionário" (CNBB, 2008, p. 47). Um terceiro argumento é que cada tipo de organização, dado a sua natureza de atuação, apresentará configurações organizacionais diferentes. Tendo em vista suas peculiaridades enquanto estrutura de ação dos sujeitos nelas atuantes, seus mecanismos de coordenação, seus parâmetros de organização do trabalho, sua atividade-fim e seus objetivos.

Por assim dizer, sustentamos o argumento que as organizações estão sempre em mudança, quebrando os pressupostos e os conceitos ditos como certos, acabados e delimitadores da realidade organizacional. 
Fugimos do entendimento de que as organizações são todas semelhantes, nos quais os elementos organizacionais são (ou já foram), por sua vez, estudados e entendidos por completos, que os fatores externos às organizações são estáticos, imutáveis, isto é, uniformes, ausente de mudanças situacionais (Mintzberg, 1981, 2003).

Assim, recorremos ao estudo dos tipos de estruturas organizacionais de Mintzberg (1981, 2003), para compreendermos o modo de organizar interno de uma organização religiosa de natureza católica. Para entender esse funcionamento, recorremos aos conceitos de mecanismos de coordenação, parâmetros do design organizacional, e fatores situacionais, para assim propormos uma estrutura organizacional a partir das peculiaridades existentes.

Desse modo, organizamos o trabalho em seis seções, incluindo a presente introdução. A próxima seção discute a estrutura organizacional a partir das partes organizacionais coordenadas, os parâmetros que delimitam a estrutura e os fatores situacionais que a influencia e logo após há a seção que discute as tipologias estruturais. Na seção seguinte são apresentados os procedimentos metodológicos. Ainda, a seção que segue apresenta os resultados e discussões do estudo e, por fim, expomos as considerações finais.

\section{A Estrutura Organizacional em Partes Coordenadas}

A ideia de organização que trataremos aqui está ligada ao ajuntamento de pessoas com comportamentos direcionados a atingir objetivos (Stoner\&Fremam, 1999; Sobral \&Peci, 2008; Maximiano, 2010). Entendemos, também, que é possível compreender as organizações através de categorias-conceitos de análises organizacionais que nos permitem traçar o formato da estrutura organizacional a partir do somatório dos departamentos da organização coordenadas para o trabalho. Assim, as organizações, independentemente da área de atuação social, apresentam impactos nos âmbitos social, histórico, econômico e cultural nas sociedades em que estão inseridas.

Dessa forma, a partir da metodologia de análise organizacional de Mintzberg (1981, 2003), compreendemos que as organizações podem apresentar partes que se conectam e as estruturam. Estrategicamente, no comando organizacional, está a cúpula que governa, responsável por elaborar os planos de ação organizacional, garantindo-lhe aplicabilidade e eficiência na realização das metas estabelecidas. A cúpula estratégica tem a responsabilidade de relacionar os contextos ambientais externos e internos da organização, coordenando as atividades dos indivíduos dentro e fora dela.

O núcleo operacional, por sua vez, processa os inputs em outputs, realiza os objetivos, coloca os planos em prática e dá vida a organização como ambiente de trabalho coordenado com pessoas alocadas no fluxo do tempo e espaço. Já a linha intermediária, afirma Mintzberg (1981, 2003), é formada por coordenadores intermediários que exercem autoridade formal sobre o núcleo operacional, mas estão sujeitos à cúpula estratégica. É importante ressaltar que a interligação entre o núcleo operacional e a cúpula estratégica é desempenhada pela linha intermediária, admitindo que exista unicidade no planejamento e práticas organizacionais (Mintzberg, 1981, 2003).

A tecnoestrutura é feita por peritos que trabalham com o objetivo de padronizar os processos, resultados e/ou habilidades, com o intuito de tornar as atividades de outras pessoas mais eficientes (Mintzberg, 1981, 2003). Por sua vez, a assessoria de apoio é uma espécie de unidade especializada com a ocupação em dar suporte ao fluxo operacional do trabalho da organização, por exemplo, os serviços de segurança patrimonial e assessoria jurídica (Mintzberg, 1981, 2003).

Desse modo, a estrutura organizacional pode ser analisada a partir da forma que as atividades são divididas e coordenadas, de maneira que a coordenação é também entendida como "a cola que mantém a organização unida" (Mintzberg, 2003, p. 14). Sendo assim, entendemos a dependência que todas as organizações têm dos mecanismos de coordenação, classificados e usados como ferramentas gerenciais que visam estimular o trabalho pautado no engajamento dos indivíduos. Isso nos faz pensar sobre o ajustamento mútuo, de caráter informal, que perpassa a estrutura formal da organização e faz com que as atividades sofram interferência direta da subjetividade dos indivíduos quanto aos afetos, desejos e inquietações enquanto grupos organizacionais (Mintzberg, 1981, 2003). Por isto, é comum a supervisão direta acontecer, principalmente com o aumento da complexidade, por ser necessária a presença de pessoas que têm a competência de instruir e monitorar as pessoas no trabalho, estando intimamente ligado à linha intermediária da organização. 
A padronização dos processos de trabalho, resultados e/ou habilidades são meios de dominar o fluxo das atividades presentes nas organizações em variados graus. A padronização, assim como o ajustamento mutuo e a supervisão direta somados as partes da organização que elencamos acima (cúpula estratégica, núcleo operacional, tecnoestrutura e assessoria de apoio), são fundamentos de análise organizacional para compreendermos a estrutura de diferentes organizações. Estes conceitos propostos por Mintzberg (1981, 2003) servem de base para observarmos a coordenação que promove a integralização entres os departamentos organizacionais.

Contudo, a estrutura organizacional com partes coordenadas, como afirma Mintzberg $(1981,2003)$ e corroboram Aguiar e Martins (2006), é melhor entendida quando analisamos a consistência entre parâmetros de design e fatores contingenciais que operam diretamente no comportamento dos indivíduos dentro do ambiente de trabalho. Desse modo, nas próximas subseções trataremos das variáveis atreladas aos parâmetros de design e aos fatores circunstanciais.

\subsection{Os parâmetros da Estrutura Organizacional}

Para melhor análise de uma organização, a partir das ideias propostas por Mintzberg (2003), é indispensável conhecer os parâmetros de design. Estes são entendidos como meios que induzem a divisão e coordenação das tarefas, os quais, como já mencionado, são considerados elementos básicos no entendimento da estrutura organizacional. Como mostra o quadro 1, são um total de nove parâmetros de design, sendo divididos em grupos para melhor compreensão. Existem os designs das posições, da superestrutura, dos vínculos laterais e dos sistemas de tomada de decisões.

Quadro 1: Parâmetros de design.

\begin{tabular}{|c|c|}
\hline \multirow{2}{*}{ Grupo } & Parâmetro de design \\
\hline \multirow{2}{*}{ Design das posições } & Especialização da tarefa \\
\hline \multirow{2}{*}{ Design da superestrutura } & Formalização do comportamento \\
\cline { 2 - 2 } & Treinamento e doutrinação \\
\hline \multirow{2}{*}{ Design dos vínculos laterais } & Agrupamento em unidades \\
\cline { 2 - 2 } & Tamanho da unidade \\
\hline \multirow{2}{*}{ Design do sistema de tomada de decisões } & Sistema de planejamento e controle \\
\cline { 2 - 2 } & Instrumentos de vínculo \\
\cline { 2 - 2 } & Descentralização vertical \\
\hline
\end{tabular}

Fonte:Adaptado de Mintzberg (2003, p. 37).

No quadro 1, o primeiro grupo, o design das posições, contêm três critérios, os quais iniciam-se com o parâmetro da especialização da tarefa. Este parâmetro apresenta-se na dimensão horizontal entendida como o desenvolvimento de trabalhadores eficientes em uma ou poucas etapas dos processos organizacionais. Quando falamos da dimensão vertical estaremos relacionando-a a ideia de poder/controle sobre o trabalho, no qual os sujeitos estão posicionados na execução das atividades nas organizações (Mintzberg, 1981, 2003). Ainda sobre a especialização da tarefa, precisamos destacar que é possível existir a ampliação das atividades tanto na dimensão horizontal quanto na vertical, o que leva ao aumento de tarefas.

$\mathrm{Na}$ formalização do comportamento a ideia é que, em menor ou maior grau, o comportamento seja homogeneizado, de forma que sejam facilitados os processos de controle que, como afirmam Aguiar e Martins (2006), permitem a consistência diante dos demais fatores dentro da organização. $O$ terceiro parâmetro do primeiro grupo é referente ao treinamento e doutrinação, os quais são interpretados respectivamente como o ensino do conhecimento técnico especializado para o pleno exercício laboral e as instruções no tocante às normas organizacionais (Mintzberg, 1981, 2003).

O grupo de design da superestrutura tem por objetivo delinear ideias que estão contidas no organograma, como a departamentalização, estrutura de comunicação e poder formal, amplitude de gerência, entre outros (Mintzberg, 1981, 2003). Para isso, tem-se o agrupamento em unidades, que pode ser por conhecimento e habilidade, por processo de trabalho, por função, por resultado, por cliente etc. O tamanho da unidade nada mais é do que a dimensão de cada unidade de organização. 
No design de vínculos laterais, é possível verificar como as organizações planejam e controlam as questões importantes e como funcionam os relacionamentos interpessoais. Sendo assim, recorre-se à análise dos sistemas de planejamento e controle que ajudam a garantir um bom desempenho organizacional. Já os instrumentos de interligação, favorecem de modo formal e informal a troca de informação entre os colaboradores por meio de cargos de interligação, comitês e estruturas matriciais, por exemplo (Mintzberg, 1981, 2003).

No último grupo que é referente ao design do sistema de tomada de decisões, o qual trabalha o conceito de descentralização. Como mostra o quadro 1, a descentralização apresenta-se nos sentidos vertical e horizontal. No sentido vertical, para Mintzberg (1981, 2003), entende-se como a distribuição do poder formal dentro da cadeia de autoridade, ou seja, é a delegação de poder para a linha intermediária, para os gerentes; por parte da cúpula estratégica. Já a descentralização horizontal é compreendida como a distribuição do poder para os não gerentes, ou melhor, para aqueles que estão no núcleo operacional, assessoria de apoio e tecnoestrutura.

Vale frisar que o processo de descentralização tanto vertical como horizontal podem ocorrer de modo holístico, mas também de maneira seletiva. Assim, os parâmetros de design são, para nós, uma forma de melhor delimitar a estrutura organizacional frente aos fatores situacionais, estabelecendo formas de traçar a eficiência e eficácia das organizações a partir de suas particularidades.

\subsection{Os Fatores Situacionais que influenciam a Estrutura}

Há um entendimento bastante estabelecido que uma organização eficaz é aquela que consegue gerar resultados, ou seja, alcançar determinados objetivos (Stoner\&Fremam, 1999; Maximiano, 2010). Alinhado a esta visão, Mintzberg $(1981,2003)$ diz que uma organização eficaz deve ter seus parâmetros de design coerentes entre si, mas não somente, pois precisam ser harmônicos com os fatores contingenciais. Estes fatores que permeiam qualquer organização estão dentro de quatro classificações: idade e tamanho, sistema técnico, ambiente e poder.

A idade e o tamanho da organização são fatores que interferem diretamente na estrutura, pois na medida em que se aumenta o tamanho e/ou a idade, verifica-se, por exemplo, o crescimento no nível de formalização dos processos, treinamento e formalização do comportamento dentro da organização. Já com relação ao sistema técnico, que são os processos para tornar os inputs em outputs (Mintzberg, 1981, 2003), exerce-se maior influência sobre o trabalho do núcleo operacional, de tal forma que se a atividade laboral é altamente regulamentada, assim, teremos uma estrutura burocratizada, se as operações forem automatizadas teremos uma organização mais orgânica e se o trabalho for altamente complexo, certamente, teremos colaboradores com maior liberdade, ou seja, haverá descentralização.

O fator ambiente é compreendido como tudo que está fora da organização - no compilado feito por Stoner e Fremam (1999) seriam os stakeholders externos e o ambiente de ação indireta - mas Mintzberg (1981, 2003) chama a atenção para análise de quatros pontos que são esquecidos muitas vezes: a estabilidade, a complexidade, a hostilidade e a diversidade do ambiente no qual está inserida. Uma vez que estes pontos refletem na estrutura organizacional.

Referente às relações de poder, podemos ter três âmbitos de análises: o controle externo sobre a organização, e necessidade de poder das pessoas que estão no ambiente interno e a influência que a moda quanto aos modelos administrativos tem sobre a organização. De um modo geral, as partes das organizações coordenadas encontram nos parâmetros que delimitam a estrutura e nos fatores situacionais caminhos para compreender seu funcionamento externo e interno e traçar características frentes os tipos diversos de estruturas organizacionais (as quais serão apresentadas na seção seguinte). Estes caminhos, nada mais são do que indicadores de desempenho da organizacional como a eficiência e a eficácia.

\subsection{Tipologia Estrutural}

Após discorrer sobre as partes da organização, os mecanismos de coordenação, os parâmetros que delimitam a estrutura e os fatores situacionais, é necessário compreender como isto pode funcionar em conjunto, convivendo de maneira dinâmica. Por esta razão, Mintzberg $(1981,2003)$ propõe um modelo com cinco tipologias estruturais para as organizações. A primeira é a estrutura simples, nela geralmente 
encontramos estruturas jovens e pequenas, coordenadas por supervisão direta (por parte da cúpula estratégica), centralizadoras, com pouco planejamento, controle, especialização, treinamento, doutrinação e elementos de ligação. O sistema técnico é tão simples como a estrutura, a qual está no ambiente simples e dinâmico, mas também podendo ser hostil.

Seguindo a ordem proposta pelo autor, temos a burocracia mecanizada. A padronização do trabalho é principal meio de coordenação nessa estrutura, por isto a tecnoestrutura tem grande importância no estabelecimento dos processos mais eficientes. Neste tipo de arranjo, percebemos também o uso do planejamento das ações, a especialização das tarefas ocorre nos sentidos horizontal e vertical, o agrupamento é funcional, o comportamento é formalizado e existe uma centralização vertical, mas com relativa descentralização horizontal.

Com relação aos fatores situacionais, nos diz Mintzberg (1981, 2003) que normalmente organizações da burocracia mecanizada são antigas e grandes, encontram-se em um ambiente estável, que aplicam um sistema técnico regulado, contudo não automatizado e, por fim, verifica-se um frequente controle externo, mas as organizações não se sujeitam à moda.

A terceira categoria é a burocracia profissional. Mintzberg $(1981,2003)$ afirma que em termos contingenciais se têm: um ambiente complexo e estável, com sistema técnico desregulado e não sofisticado e com organizações que podem variar em termos de idade e porte. A padronização das habilidades é o principal meio de coordenação, logo há uma descentralização vertical e horizontal porque o núcleo operacional (parte-chave da burocracia profissional) é altamente especializado horizontalmente, por meio do acentuado uso de programas de treinamentos, os quais fazem com que a organização possa confiar no núcleo operacional, pois conhece suas capacidades técnicas.

A quarta estrutura é a forma divisionada. Ela tem sua coordenação baseada na padronização dos resultados (ou seja, tem um sistema de controle de desempenho rigoroso), os quais devem ser acompanhados pelos gerentes (isto é, há uma descentralização do poder da cúpula para a linha intermediária), pois este tipo de estrutura é uma espécie de organização semiautônoma com o propósito de melhor atender um determinado mercado, mas que ainda estão sob a jurisdição externa. Para que uma estrutura deste tipo seja eficaz é necessário que exista um alto nível de maturidade, o qual, quase sempre, é fruto de um considerável tempo de existência e volumoso tamanho (Mintzberg, 1981, 2003).

A quinta e última tipologia estrutural proposta por Mintzberg $(1981,2003)$ é a forma denominada de adhocracia. " $A d$ hoc" é uma expressão do latim que o autor usa para expressar algo que tem um propósito de caráter temporário, ou seja, é uma estrutura que tem por missão atender um objetivo e brevemente ser desfeita. Desta forma, adhocracia é sinônimo de estruturas jovens. O mecanismo de coordenação mais empregado é o ajustamento mútuo, as pessoas envolvidas são extremamente peritas no que fazem, a organização usa demasiadamente o treinamento e instrumentos de interligação, pois estamos falando de equipes de conhecimentos múltiplos e profundos, além de uma assessoria de apoio presente, tendo em vista que o sistema técnico utilizado é sofisticado e geralmente automatizado (Mintzberg, 1981, 2003). Além disto, vale destacar que o ambiente é complexo e dinâmico.

Dessa forma, é importante destacar que os tipos de estruturas organizacionais proposto por Mintzberg $(1981,2003)$ são delimitações ideais, encontrando respaldo na realidade das organizações de forma variadas, com características pertencentes a mais de um tipo de estrutura. O que nos faz pensar na importância de se entender como as organizações se desenvolvem no seu cotidiano, com suas variáveis estruturais que se relacionam entre si e estabelecem a forma de realização do trabalho na habitualidade.

\section{Procedimentos Metodológicos}

A discussão levantada por esse estudo está norteada pela necessidade de atentar os olhares da administração para as organizações religiosas, visualizando esse tipo de organização como sendo instituições centrais na sociedade com forte influência política, cultural e social. Assim, mais do que revisitar a teoria tipológica das estruturas organizacionais de Mintzberg $(1981,2003)$, buscamos nessa pesquisa entendê-las a partir de uma organização religiosa de natureza católica no interior do Estado de Pernambuco através dos mecanismos de coordenação, os parâmetros de design e os fatores situacionais que influenciam interna e externamente o funcionamento da organização. 
Optamos por uma pesquisa qualitativa explicativo-interpretativa, pois tem como pretensão central identificar os fatores que contribuem para com que o fenômeno estudado aconteça e assim aprofundarmos o conhecimento sobre a realidade social (Gil, 2002). Como afirma Merriam (2009) à pesquisa qualitativa é ainda uma forma de compreender como os sujeitos dão sentido às suas vidas, construindo significados e também os compartilhando, neste caso, dentro de uma estrutura organizacional.

A entrevista foi utilizada como procedimento metodológico, pois permite que o pesquisador entre em uma conversa informal com os sujeitos entrevistados enriquecendo a prática da pesquisa e construindo novas situações de conhecimento (Godoi \& Mattos, 2010). As entrevistas realizadas foram todas semiestruturadas, ou seja, os pesquisadores portaram consigo dois roteiros contendo perguntas previamente elaboradas que guiaram todas as conversas informais. Durante a realização das entrevistas, novas perguntas foram feitas pelos pesquisadores que não necessariamente estavam nos roteiros e, também, a ordem em que foram feitas as perguntas variavam de acordo com o desenvolvimento e a interação que acontecia entre o pesquisador e o sujeito pesquisado.

É importante ponderar, também, que existiu dois roteiros, um roteiro com um grupo de perguntas que foi direcionado ao padre e um outro roteiro com um novo grupo de perguntas que foi direcionado aos outros indivíduos envolvidos no desenvolvimento do trabalho pastoral. Os roteiros continham perguntas que versavam sobre administração, planejamento, atividades realizadas, delegação de funções, hierarquia, controle, desempenho e liderança organizacional. A escolha dessa paróquia, como organização religiosa para a pesquisa, ocorreu porque como a instituição social apresenta forte influência no comportamento dos indivíduos que a frequenta, na cidade de Passira no agreste de Pernambuco, no qual está situada.

Ao todo, foram realizadas seis entrevistas e o quadro 2 mostra os detalhes através do código de identificação do nome dos sujeitos entrevistados, o grupo e/ou o cargo organizacional ao qual fazem parte, o local em que a entrevista foi realizada e a data. Todas as entrevistas foram gravadas com autorização e, posteriormente, transcritas pelos pesquisadores, sendo a transcrição o material empírico analisado. Dada à peculiaridade que o padre aparenta ter sobre seus seguidores, as entrevistas foram realizadas com o secretário e os coordenadores de pastorais e movimentos religiosos. Isto porque estes sujeitos estão na linha subjacente da hierarquia organizacional.

Quadro 2. Entrevistas realizadas.

\begin{tabular}{|c|c|c|c|}
\hline $\begin{array}{c}\text { Código dos } \\
\text { entrevistados }\end{array}$ & Cargo e/ou grupo organizacional a que pertence & Local da entrevista & $\begin{array}{c}\text { Data da } \\
\text { entrevista }\end{array}$ \\
\hline Padre & Padre & Casa Paroquial & $12 / 10 / 2017$ \\
\hline CP1 & Coordenador da Pastoral da Juventude & Casa do sujeito. & $14 / 10 / 2017$ \\
\hline SEC & Secretária & Sacristia da paroquia. & $21 / 10 / 2017$ \\
\hline CP2 & Coordenador da Pastoral da Liturgia e do movimento & Centro de catequese. & $21 / 10 / 2017$ \\
\hline CP3 & “treinamento e liderança cristã” (TLC). & Casa do sujeito. & $28 / 10 / 2017$ \\
\hline CP4 & Coordenador da pastoral da comunicação. & Casa do sujeito. & $30 / 10 / 2017$ \\
\hline
\end{tabular}

Fonte: Elaborado pelos autores.

Os indivíduos entrevistados foram os que possuíam fácil acesso e disponibilizavam de tempo para receber os entrevistadores. A técnica analítica empregada foi à análise de conteúdo, em que foram separados os trechos das falas dos entrevistados por categorias conceituais que se assemelhavam quanto a sua essência e significado. As categorias conceituais foram norteadas pelos conceitos-chaves da metodologia de estudo de estruturas organizacionais de Mintzberg $(1981$; 2003) como os mecanismos de coordenação, os parâmetros de design organizacional e os fatores ambientais. 


\section{Resultados e Discussões}

\subsection{A Estrutura Organizacional pensada a partir de suas Partes Coordenadas}

Em uma realidade local de uma organização religiosa de natureza católica de atuação no Estado de Pernambuco, podemos observar a existência de níveis na estrutura administrativa o qual essa organização é subordinada. Estes níveis, a título de conhecimento, são o regional, nacional e mundial representados, respectivamente, pela Diocese de Nazaré da Mata, a CNBB (Conferência Nacional dos Bispos do Brasil) e a cidade-estado do Vaticano, na qual é localizada a administração central que une os preceitos de comando das instituições católicas.

No entanto, pensamos a estrutura administrativa da organização religiosa em estudo a partir da mobilização gerencial dos indivíduos no âmbito local, centradas nas práticas de gestão dos grupos organizacionais. Durante o período de inserção de estudo em campo conseguimos levantar, a partir das conversas informais, um total de 15 grupos funcionais e seu segmento de atuação como mostra o quadro 3 . Os grupos listados estão todos em funcionamento e recebem nomes específicos de acordo com a área em que atuam prestando serviços apostólicos. Estes agrupamentos são pensados a partir das diretrizes programáticas da igreja a nível mundial, mas que são abertas para adesão de pessoas que escolhem livremente de qual grupo participar.

Quadro 3: Agrupamentos funcionais e eixo de atuação na paróquia.

\begin{tabular}{|c|c|c|}
\hline \multicolumn{3}{|c|}{ Organização interna por agrupamento da paróquia } \\
\hline Numeração & Grupos Apostólicos & Eixo de Atuação \\
\hline 1 & Secretária & Serviço apostólico de organização administrativa paroquial \\
\hline 2 & Pastoral da Juventude (PJ) & $\begin{array}{l}\text { Serviço apostólico de atendimento de ensinamento cristão a } \\
\text { juventude }\end{array}$ \\
\hline 3 & Pastoral da Liturgia & $\begin{array}{l}\text { Serviço apostólico de fundamentação bíblica e organização do } \\
\text { culto }\end{array}$ \\
\hline 4 & Pastoral da Família & $\begin{array}{l}\text { Serviço apostólico de atendimento de ensinamento cristão e } \\
\text { preservação da família }\end{array}$ \\
\hline 5 & Pastoral da Criança & $\begin{array}{l}\text { Serviço apostólico voltado a promoção do desenvolvimento } \\
\text { integral de crianças entre } 0 \text { e } 6 \text { anos de idade em seu ambiente } \\
\text { familiar e em sua comunidade. }\end{array}$ \\
\hline 6 & Pastoral da Catequese & Serviço apostólico formação cristã básica (Catequese e Crisma) \\
\hline 7 & Pastoral da Comunicação & Serviço apostólico voltado a dar publicidade as ações da paróquia \\
\hline 8 & $\begin{array}{l}\text { Movimento Treinamento de } \\
\text { Liderança Cristã (TLC) }\end{array}$ & $\begin{array}{l}\text { Serviço apostólico voltado para evangelização do jovem e } \\
\text { intervenção social }\end{array}$ \\
\hline 9 & $\begin{array}{c}\text { Movimento Renovação } \\
\text { Carismática Católica (RCC) }\end{array}$ & $\begin{array}{l}\text { Serviço apostólico oferecem uma abordagem inovadora às formas } \\
\text { tradicionais de doutrinação e dos ritos da igreja. }\end{array}$ \\
\hline 10 & $\begin{array}{l}\text { Encontro de Casais com Cristo } \\
\text { (ECC) }\end{array}$ & $\begin{array}{l}\text { Serviço apostólico voltado a casais e à instituição e preservação } \\
\text { do matrimônio }\end{array}$ \\
\hline 11 & Apostolado da Oração & $\begin{array}{l}\text { Serviço apostólico com a finalidade da santificação pessoal e a } \\
\text { evangelização }\end{array}$ \\
\hline 12 & Oficina de Oração & $\begin{array}{c}\text { Serviço apostólico do ensinamento de orar de uma maneira } \\
\text { ordenada, metódica e sistemática }\end{array}$ \\
\hline 13 & $\begin{array}{l}\text { Ministros Extraordinários da } \\
\text { Sagrada Comunhão Eucarística } \\
\text { (MESCE) }\end{array}$ & $\begin{array}{l}\text { Serviço apostólico voltado a distribuição a comunhão aos fiéis } \\
\text { nas celebrações eucarísticas }\end{array}$ \\
\hline 14 & Coroinhas & Serviço apostólico de apoio ao pároco em celebrações religiosas \\
\hline 15 & Encontro Terço dos Homens & Serviço apostólico voltado ao público masculino de oração e reza. \\
\hline
\end{tabular}

Fonte: Elaborado pelos autores.

Os coordenadores das pastorais, ou unidades funcionais, apresentam formação profissional diretamente ligada aos eixos de atuação das unidades que coordenam. Como o coordenador da pastoral da comunicação é radialista, a pastoral da juventude e da catequese e crisma são professores, assim como a secretária que passou por treinamentos para melhor planejar e desenvolver as atividades locais. $\mathrm{O}$ que corrobora com o entendimento de Mintzberg (2003) que nas estruturas burocratizadas as pessoas podem ser 
agrupadas a partir de seus conhecimentos e habilidades técnica e humana, facilitando a coordenação a nível grupal.

Para Mintzberg $(1981,2003)$ uma organização pode ter até cinco partes, mas na paróquia aqui analisada, como mostra a figura 1, percebemos a existência de apenas três partes: (1) cúpula estratégica, (2) linha intermediária e (3) núcleo operacional. A cúpula estratégica é parte da organização que é bastante personificada, pois há um único indivíduo que é o padre líder maior local. Para compreender a figura do padre é preciso distinguir dois âmbitos de atuação do mesmo, a atuação de líder gestor e de líder espiritual.

Figura 1: As partes da paróquia.

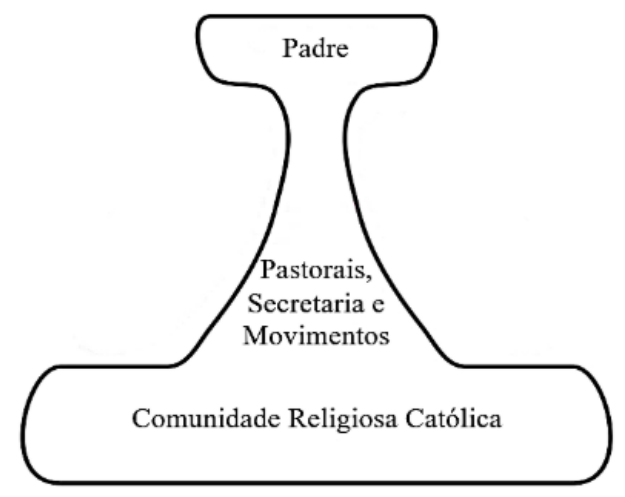

Fonte: Adaptado de Mintzberg (1981, p. 106)

A função de gestor está ligada às funções propriamente da administração, pois é necessário elaborar o planejamento das diversas atividades, organizar as pessoas e os recursos para executar tais atividades, liderar a comunidade, sendo necessário "fazer com que as pessoas abracem a causa de Deus, porque o povo [...] se anima, se empolga e [...] se retrai" (Entrevistado: Padre) e verificar se as atividades estão sendo devidamente realizadas. A função ganha importância pelo fato que o padre sempre foi engajado em ações religiosas que exigem muito esforço técnico e administrativo para cativar os indivíduos às realizações, como a construção de uma nova igreja matriz que, na fala da secretária paroquial, "é a construção maior de nossa cidade"' (SEC)

Contudo, verificamos por meio dos discursos dos entrevistados a importância que se dá ao papel de líder espiritual, em especial, porque "a figura do padre pra comunidade, pra mim é uma figura de pai. É aquele que orienta, é aquele que faz as correções nos momentos oportunos, mas é aquele que tá ali ao seu lado" (CP3) e a visão que "a pessoa do padre é a pessoa de Jesus Cristo em nosso meio" (CP3). Ou seja, a partir destes trechos, notamos que o padre extrapola suas funções clássicas ao ponto de tornar-se membro do rol de amigos íntimos dos seus liderados, exercendo uma liderança baseada no conhecimento de vida dos coordenadores e fiéis, no apoio enquanto cristão moral, no orientador, ou nas palavras de Mintzberg (2003), no ajustamento mútuo.

A segunda parte da organização é a linha intermediária, no qual encontramos três grupos: (1) as pastorais que são no total de seis (como mostra o quadro 3) que tem a função de organizar as atividades de caráter mais repetitivas e previsíveis, por exemplo, a Pastoral da Liturgia segue um padrão de preparação do culto a Deus que está estabelecido pelo Vaticano, (2) a secretaria que é ocupada por uma única pessoa que tem a função de organizar a agenda do padre e atender às diversas demandas de ordem administrativa e (3) os movimentos que, como o nome já remete, tem a característica de desempenhar programações especiais que objetivam estimular os fiéis com alguma finalidade.

Por fim, a terceira parte é ocupada pela comunidade religiosa católica, isto é, os fiéis que trabalham de forma voluntária. Estes executam as atividades elaboradas pelo padre sob a coordenação dos membros da linha intermediária, ou seja, formam o núcleo operacional. Por exemplo, cabe ao padre à definição do calendário de atividades anuais, dentro deste sempre está à festa da Imaculada Conceição que é a padroeira da cidade. Mas, a realização de um evento deste porte necessita de muitas pessoas, uma vez que é preciso preparar a estrutura física, comprar ou alugar produtos necessários que a igreja não tenha, realizar a 
divulgação, entre outras atividades que são delegadas à linha intermediária e essa juntamente com os fiéis coloca em pratica as atividades que foram planejadas.

Diante dessa configuração organizacional, percebemos que pelo fato de a igreja se organizar em agrupamentos funcionais pequenos, favorece o ajustamento mútuo quando observamos que existe uma descentralização de tarefas pouco especializadas, podendo ser feitas pelas pessoas em seus agrupamentos ou em agrupamentos diferentes que precisem de ajuda. O que posiciona as pessoas na estrutura por grupos de modo a não perder o caráter colaborativo e solidário, típicos dessas organizações, e que ao mesmo tempo em que a amplitude de controle e coordenação sobre as estruturas dos grupos funcionais apresentam uma supervisão direta ajustada às necessidades do momento, aos objetivos da organização, pensando-a eficazmente (Mintzberg, 1981, 2003).

Vale ressaltar que dentro deste núcleo operacional há uma grande variedade no grau de atuação, ao ponto que existem pessoas que estão no núcleo operacional, mas, informalmente, assistem a linha intermediária de forma expressiva. Além disto, destaca-se uma peculiaridade desta organização religiosa: os membros de todos os níveis trabalham na organização também são consumidores dos serviços prestados, pois de modo geral podemos entender que a missão da paróquia é de conhecer a Deus e fazê-lo conhecido.

Assim, aos mecanismos de coordenação dessa estrutura paroquial, identificamos um desenho hierárquico fortemente e claramente posto, além da consciência da importância disto para a organização por parte dos membros na linha intermediária, por exemplo, na fala do Coordenador da PASCOM: "tudo tem que ter hierarquia, se deixar vira bagunça" (CP3). A supervisão direta se faz presente até porque, sobre a liderança do padre, a Secretária diz que "ele sempre tá por dentro das coisas, quando uma coisa não tá do jeito que ele quer, ele corre atrás pra acontecer do jeito dele" (SEC) e a Coordenadora da Pastoral da Catequese expõe que "nada na pastoral realiza sem a orientação do padre" (CP4). Como já apontamos, o ajustamento mútuo e a supervisão direta caracterizam a estrutura hierárquica da organização.

Embora o padre se faça presente nas ações da instituição, a supervisão direta funciona de modo frouxo, sobretudo, com relação ao padre sobre a linha intermediária. $\mathrm{Na}$ visão do padre, isto ocorre pois ele encontra-se "diante de um povo que me respeita e que eu respeito o povo [...]. Porque a liderança, ela se conquista e a gente se torna um líder na comunidade ouvindo as pessoas, respeitando as opiniões [...] eu não gosto de negócio de gritar ninguém não, eu converso com as pessoas" (Entrevistado: Padre). Porém, o nível de liberdade de decisão depende da temática, por exemplo, "se for um assunto que vá ferir qualquer aspecto a nível de doutrina, de dogma da igreja, algum assunto que seja, vamos dizer, que gere um problema, que extrapole o grupo, aí a gente tem que passar pelo crivo, pela opinião do padre (CP1).

Logo, percebemos a existência de relações com alto grau de confiança e proximidade entre líder e liderado, fortalecido pela ausência de sanção de caráter financeiro, até porque as atividades organizacionais não são renumeradas. Esta conjuntura favorece algo cuja presença é extrema: uma comunicação informal tanto verticalmente, entre as camadas hierárquicas, como horizontalmente - dentro do mesmo nível hierárquico (Mintzberg, 1981, 2003). A título de amostra, o Coordenador da Pastoral da Juventude descreve o uso de aplicativos de comunicação para poder organizar as atividades de sua pastoral e relacionar-se com as outras pastorais. Desta forma, portanto, temos o ajustamento mútuo também como mecanismo de coordenação, mas dado a sua importante presença, consideramos ele como o principal mecanismo de coordenação da paróquia aqui examinada.

Todavia, não podemos negligenciar os outros instrumentos, pois os mesmos estão presentes dentro da estrutura, mas de modo menos perceptível e que caracterizam a estrutura da organização. Como a padronização dos processos de trabalho e de resultados pensadas a partir das atividades utilizadas para realizar uma missa, por exemplo, a qual tem praticamente todo seu conteúdo padronizado, e seu formato já pré-estabelecido. Já a padronização das habilidades pode ser pensada quanto às capacidades técnicas da linha intermediária, mas acima de tudo na formação do padre acadêmica teológica e outras que possam auxiliar em seu cotidiano. Sendo assim, na seção seguinte a estrutura organizacional será pensada a partir dos grupos funcionais e as características organizativas da paróquia que gira em torno deles.

\subsection{A Estrutura Organizacional pensada a partir da Descentralização, do Treinamento e da Doutrinação nos Indivíduos}

A Igreja Católica como instituição social parte de uma perspectiva de condição humana vinculada a uma subjetividade carregada de sentimentos de fé, amor, bondade e caridade na tentativa de orientar as ações 
humanas a partir dos ensinamentos cristãos repassados secularmente. Muito desse entendimento da condição humana sustentada pela fé no sagrado fez/faz com que a paróquia, como organização religiosa, venha se estruturando através da voluntariedade do trabalho e de quadros de ordenamento interno funcional por serviços prestados a comunidade.

Ela [a igreja] tem seu quadro assim, as pastorais sociais, as pastorais que domina mais o ponto fundamentação bíblica né, estudo né, porque ela é, está, como eu já disse, é o sinal de Deus no mundo para anunciar o reino [...] ela não tem uma estrutura, ela está se estruturando. Eu num... eu não abarcava sozinho pra coordenar e pra definir porque a gente se reúne, define as metas e eles aplicam né [....] algumas [pessoas] foram convidadas por mim, outras já vem de outras caminhadas da igreja. São pessoas que estão ali a serviço né? Porque não... nenhuma dessas pessoas é, são remuneradas, todas são de livre e espontânea vontade. E a gente... e elas fazem por amor" (Entrevistado: Padre, grifo nosso).

Assim, como já delimitamos, compreendemos que a estrutura organizacional da igreja é apoiada em unidades grupais, que são responsáveis por sistematizar os serviços que atendem as necessidades religiosas da comunidade em que está inserida. Estes grupos possuem coordenadores que fazem a intermediação entre o padre e os indivíduos fiéis adeptos ao catolicismo que dão identidade à organização e ao mesmo tempo unicidade de crenças.

Como relatado pelo padre, o trabalho desenvolvido nesses agrupamentos tem caráter de voluntariedade, isto é, livre de relações assalariadas. Os sujeitos fiéis podem, e comumente assim acontece, participar de mais de um grupo organizacional, trabalhando em objetivos partilhados. O que reforça o nosso entendimento de um trabalho pouco especializado, coordenado por uma supervisão direta mitigada, encadeada pelo padre, coordenadores e fiéis comuns participantes dos grupos, gerando uma linha hierárquica vertical de autoridade na estrutura organizacional. Mas, como afirma o sujeito-padre, existe uma harmonia entre os níveis hierárquicos, fugindo de uma compreensão de imposição de mando organizacional: "a igreja é monárquica. A igreja prega democracia, mas ela é monárquica [...] agora existe uma harmonia, ninguém impõe as coisas, hoje" (Entrevistado: Padre).

A organização das pessoas em grupos direcionados a desempenharem serviços apostólicos específicos como forma de ordenamento interno de ação fiéis da paróquia toca no entendimento de Mintzberg $(1981,2003)$ de que a base para se agrupar pessoas em unidades é entendida através das funções que desempenham como critério fundamental de agrupamento, o qual é visto na prática pela Igreja Católica em estudo. O que, desta maneira, favorece o aparecimento do ajustamento mútuo como forte meio de coordenação das atividades e serviços prestados pelos grupos. Isto porque ao se agruparem, não só partilham de medidas de desempenho e metas, como também partilham de recursos físicos e, sobretudo, espirituais garantindo o engajamento intragrupal e senso de direção uniforme que moldam a estrutura de organização interna paroquial.

Os grupos organizacionais estão submetidos a sistemas de controle comuns que auferem o andamento das atividades desempenhadas e os serviços prestadas em prol da comunidade de fiéis católicos. Evidentemente era de se esperar que a paróquia em estudo tivesse mecanismos de coordenação que mensurassem os resultados do empenho dos seus grupos apostólicos. Mas, se por um lado queremos chamar a atenção para a existência de planejamento e dispositivos de controle das ações organizacionais, por outro ressaltamos que, conforme a dinâmica da natureza da organização, os objetivos a serem traçados e alcançados estão dentro do campo subjetivo da fé ao qual não cabe sanções, punições, castigos ou qualquer outro instrumento de natureza punitiva para atividades que não foram desempenhadas como esperado pelos coordenadores em seus agrupamentos funcionais.

Até porque, neste sentido, as ações organizacionais são alimentadas pela crença na "palavra de Deus e pela Eucaristia, à luz da evangélica opção preferencial pelos pobres, para que todos tenham vida, rumo ao Reino definitivo" (CNBB, 2011, p. 9). Sendo assim, as falas dos entrevistados, apontam para um planejamento das ações a nível paroquial que servem de base para a elaboração de um planejamento dentro dos grupos apostólicos a partir de seus coordenadores. 
A gente se reúne cada mês pra avaliar e planejar. No primeiro sábado com as comunidades do interior e na primeira segunda-feira do mês na cidade com as pastorais. Avalia e começa outro [mês] de novo [...] [atividades previstas não realizadas] a gente tem que recomeçar ne? Porque não deve... porque na maioria das... noventa e nove por cento acontece. Se não acontece, não vai voltar atrás, vai continuar. Porque todo trabalho com pessoa tem, mesmo que seja planejado, ele tem falhas [...] mas nem por isso a gente vai deixar de fazer (Entrevistado: Padre, grifo nosso).

Nós fazemos reuniões mensais. De uma a duas reuniões por mês. Nessas reuniões é feito um calendário do que vai realizado naquele mês [..] então a gente senta num domingo à tarde e a gente debate o calendário do mês, quais são as atividades do mês. Essas atividades são de acordo com a tendência do calendário litúrgico da igreja. Então, se é o período pascal, a gente faz as atividades com o período pascal [...] de acordo com a disponibilidade do grupo (CP1, grifo nosso).

Da liturgia a gente mensalmente, a gente se reúne e a gente define o quea gente vai fazer durante o mês [...] no TLC também não é diferente [...] dentro do nosso planejamento paroquial a gente tem a liberdade de definir o que a gente vai fazer naqueles meses [...] , a gente atua como irmãos em Cristo, na fé, e se teve algum problema da situação de não ser cumprido aquele determinado... cronograma, então a gente faz a alteração e dá certo. Isso não quer dizer que vai ter uma sanção, vai ter uma punição por aquilo [...] não existe uma sanção, não (CP2, grifo nosso).

E a gente se reúne... uma vez... ao mês, pra avaliar, e planejar... Toda última segundafeira de cada mês, inclusive segunda é o nosso encontro. A gente se reúne às sete horas da noite, lá no centro de catequese. Todos os membros... pra gente avaliar como foi o mês que passou, tá acabando... e também planejar o mês vindouro [...] a gente faz uma avaliação de como foi o mês (CP3, grifo nosso).

Todo mês a gente senta avalia o que foi que fez, o que deixamos de fazer né. Nós tínhamos, por exemplo, uma palestra né, com um dos coordenadores e aí ele não pôde naquele dia [...] a gente senta, amarra, qual foi a palestra que não pode ser realizada e aí a gente já amarra para o mês seguinte né, deixando certo [...] a gente tá sempre organizando, o importante é não deixar de fazer, não deu aqui, porque a gente vai de acordo com a necessidade (CP4, grifo nosso).

O calendário litúrgico é temático, nele contém o tempo denominado de "forte" que possui os ciclos do advento, do natal, da quaresma e pascoal e o tempo denominado de "comum". Este calendário é repassado pelo padre para os coordenadores dos grupos apostólicos, no qual são traçados planos de ações e metas específicas para cada agrupamento. Os planejamentos se desenvolvem através das assembleias paroquiais e reuniões nos grupos apostólicos, no qual as metas e ações traçadas são também mensuradas e avaliadas quanto seu desempenho global. Assim, notamos a existência de uma metodologia organizativa (Mintzberg, 1981, 2003) que corrobora no desenho da estrutura organizacional da paróquia.

Ainda assim, os trechos das falas dos entrevistados nos evidenciam que o sistema de planejamento existente apresenta uma forte característica de autonomia de ação por parte dos coordenadores dos grupos apostólicos quanto a execução das atividades e metas traçadas, flexibilizando-as quanto à necessidade religiosa do grupo e bem-estar da organização como um todo. Em outras palavras, é perceptível que os coordenadores, assim como os outros fiéis, não se prendem apenas ao que está planejado e escrito nos grupos funcionais. Isto porque o ajustamento mútuo, como mecanismo de coordenação, faz com os indivíduos se ajudem enquanto cristãos diante das dificuldades que venham existir ao tentarem colocar em prática os eventos e serviços religiosos. A paróquia não apresenta um sistema técnico sofisticado de controle e planejamento.

Posto isto, compreendemos que a cooperação entre os indivíduos perpassa o campo formal e informal da organização, sendo ela, uma característica própria, institucionalizada pela forma de exercício da descentralização da autoridade que decorre entre a linha vertical de comando e controle. Esta característica estrutural em que os indivíduos ajudam uns aos outros, independentemente do grupo apostólico em que faz parte, é o que podemos denominar de intercomunicação pastoral, que tem o intuito de deixar a estrutura organizacional da paróquia mais concisa, coesa e consistente (Mintzberg, 1981, 2003). Comumente acontecem operações de cancelamentos de atividades previstas de um núcleo grupal apostólico pelo 
coordenador com o intuito de ajudar nas atividades de outros grupos paroquiais. Isto é, há um sentido forte de cooperação e apoio entre os agrupamentos organizacionais, flexibilizando os planejamentos com o intuito de estar sempre em estado de missão e fé (CNBB, 2011) em prol da paróquia. Como apontam os trechos das entrevistas:

Porém, a gente tem nossa autonomia de como conduzir nossos encontros [..] que tipo de encontro a gente vai dar e de que formar a gente vai dar, porém pra que a gente tenha a condução desses encontros a gente tem também formação [...] a diocese tem equipes em cada pastoral que vai formar os lideres dessas pastorais, uma capacitação e lá são orientados como deve ser o comportamento, quais são as atitudes, os calendários, as atividades da diocese, qual deve ser o comportamento (CP1, grifo nosso).

Pra o mundo a igreja católica parece ser algo muito rígido, é... muito fechado, muito dogmática, é... de rédeas, mas na verdade não é assim. A gente tem a liberdade de agir dentro das diretrizes da igreja com a nossa liberdade, da forma como a gente quer. Desde que não infrinja aquilo que a igreja tá pregando" (CP2, grifo nosso).

Ai é, no sábado de oito as onze lá no centro de catequese com ele. Ai tudo isso é formação. E tem também, os encontros a nível de diocese, lá em Carpina no CETREM, na Igreja do Bispo como eu conheci né. Geralmente é dois dias, e é só formação, muito bom. É uma pastoral assim, que ela abre um leque, sem falar que ela é/ das demais pastorais é aquela que tá centralizada. Ela tem acesso a todas as pastorais" (CP3, grifo nosso).

Veja, eu acompanho é... catequistas e auxiliares, nós damos formações mensais pra esses catequistas né? Com os documentos oferecidos pela diocese. Nós temos formações também lá, com outros coordenadores de outras é... matriz, de outras é... igrejas e lá a gente encontra toda a equipe, toda diocese de Nazaré da Mata (CP4, grifo nosso).

A gente já tem todo suporte, a gente tem reuniões preparatórias, assim, todo ano, a gente tem duas por anos e já é repassado tudo. Desde a diocese, tem os padres responsáveis que passa pra gente isso, tem toda uma formação [...] aí um dia, é repassado as coisas [...] a gente planeja antes, com um tempo de antecedência, né? Pra não dar... tempo de fazer tudo" (SEC, grifo nosso).

Esta autonomia de atuação organizacional por partes dos sujeitos-fiéis, muito existe por causa de um forte sistema de treinamento e doutrinação institucionalizado há séculos nas organizações religiosas de natureza católica. Existe toda uma formação básica dos preceitos, dogmas e regras incorporada pelos seus fiéis e reproduzidos. Quando falamos que os dogmas e regras são reproduzidos, não queremos dizer que inexiste criticidade nos indivíduos, mas pelo contrário, apesar dela, o sistema organizacional permanece firme, forte e institucionalizado, ou seja, legitimado.

A formação básica católica compreende o batismo, o catecismo e a crisma em que os fiéis, coordenadores ou não de grupos apostólicos, por estes mecanismos de aprendizado religioso, se socializam na organização, inserem os mandamentos e os preceitos em suas atuações organizacionais, aprendendo-os e reproduzindo-os, garantindo assim unicidade de crenças. Logo, se entende o porquê do forte ajustamento mútuo entre os grupos apostólicos e a descentralização de autoridade para os coordenadores, neste caso, ao organizarem e reorganizarem os planejamentos de ações e metas (Mintzberg, 1981, 2003).

Todos os coordenadores de grupos apostólicos relataram passar por diversas reuniões preparatórias antes de assumir seu posto central nos agrupamentos, e também relataram que mesmo após se tornarem coordenadores, ainda assim, passam por inúmeras capacitações, formações apostólicas, palestras, conferências e compartilhamento de experiências constantes dentro do ambiente institucional da igreja católica. Sempre se atualizando dos temas católicos, expectativas de ação e objetivos, pela instituição traçados.

Em outras palavras, a formação, como um parâmetro-chave da estrutura organizacional, é basicamente um caminho para alcançar a padronização (como consequência, também, a burocratização) do comportamento institucionalmente aceito (Mintzberg, 1981, 2003) dentro da paróquia. Isso garante não só um amplo controle interno das ações dos sujeitos que da religião católica fazem parte, como também um 
amplo controle externo do ambiente social ao qual a organização faz parte. Preservando sua estabilidade interna e externa, legitimando sua estrutura organizacional e atuando em um ambiente social estático.

Esse ambiente é construído a partir dos dogmas preservados e repassados a partir de mecanismos de controle e doutrinação, como formações básicas católica (batismo, catequese e crisma), formações apostólicas, capacitações e discursos construtores de uma organização social, histórica e cultural em que a instituições religiosas católicas agem com um forte papel de poder e mantêm a ordem social, a partir do foro clerical, na formalização das crenças católicas presente na matriz das sociedades ocidentais por estas crenças formuladas, construídas e influenciadas (Cardim, 2001; Woods Jr., 2008).

Assim, apontamos o mecanismo de ajustamento mútuo como forte meio de coordenação dos parâmetros de design organizacional, também influenciado por uma supervisão direta mitigada que atuam frente aos agrupamentos funcionais, e uma descentralização de autoridade na linha vertical das hierarquias da estrutura de mando da paroquial, uma vez que a linha intermediária detém certa autonomia. Estruturas estas harmônicas entre si, isto é, com uma intensa colaboração entre os indivíduos através da intercomunicação pastoral institucionalizada.

O sistema de planejamento e controle é formalizado a partir de uma forte autonomia dos seus coordenadores apostólicos, programando e reprogramando, dentro das diretrizes da paróquia, ações e metas a nível grupal. Uma autonomia proveniente de um rígido sistema de doutrina e treinamento aos sujeitos-fiéis determinada pela estrutura organizacional da igreja católica é observada, garantindo um senso de direção uniforme e coeso de seus seguidores.

Com isto, pensamos uma organização religiosa a partir da teoria das estruturas organizacionais proposta por Mintzberg $(1981,2003)$, resultando de um predomínio da estrutura burocrática com traços característicos de organização por agrupamentos funcionais a partir das habilidades dos indivíduos, uma comunicação informal tanto verticalmente (entre as camadas hierárquicas) como horizontalmente (dentro do mesmo nível hierárquico) e com o sistema de planejamento apresentando forte característica de autonomia aos indivíduos provenientes da descentralização da autoridade da figura do padre. Figura esta que se apresenta em dois âmbitos de atuação, tanto a nível de líder gestor quanto a nível de líder espiritual. Com uma linha intermediária atuante, na figura dos coordenadores dos grupos apostólicos e com uma comunicação interpastoral que influencia a estrutura formal da organização, dando-lhe uma estrutura organizacional complexa, múltipla e polifórmica.

\section{Considerações Finais}

Compreender uma organização religiosa de natureza católica a partir de modelos de cunho organizacional-administrativo não é algo muito comum, mas necessário para o desenvolvimento de pesquisa em administração. Por isto, desenvolvemos esta pesquisa a partir do questionamento de como pensar uma organização religiosa a partir da teoria das estruturas organizacionais em Mintzberg, buscando entender suas características internas que dão forma a sua identidade social, cultural e histórica.

O modelo de Mintzberg (1981, 2003) é uma ferramenta importantíssima no entendimento macro da instituição e como um modelo foi usado como lente teórica para analisar a organização religiosa católica objeto desse estudo, que além de todos os fatores subjetivos que permeiam quaisquer organizações, tem a fé como força motriz, a qual nem mesmo indivíduos participantes dessas instituições religiosas conseguem defini-la de modo objetivo, dado a sua subjetividade e sua capacidade de influenciar comportamento sociais a tempo naturalizados.

O resultado da análise mostrou como a organização estrutural da instituição religiosa por nós estudada apresenta características da burocracia em Mintzberg (1981, 2003) por agrupamentos funcionais, com forte autonomia dos indivíduos, tendo como mecanismo de coordenação o ajustamento mútuo a através de uma intercomunicação pastoral que perpassa o ambiente formal e informal da organização, já legitimada e institucionalizada pelos indivíduos, sendo esta intercomunicação na estrutura característica própria baseado nos valores de solidariedade e colaboração.

No entanto, pensar nas organizações, a depender de sua natureza de atuação social, é importante porque evidencia outras formas de se organizar, de olhar as estruturas organizacionais, contribuindo para que se amplie o debate e os estudos em administração para além da convencionalidade e comodismo nas pesquisas sobre as organizações e seus funcionamentos já postos. Organizações com características de trabalho voluntário, subjetividade da fé, indivíduos que atuam na solidariedade, no apoio ao outro, por 
exemplo, são variáveis que instigam a investigação científica ao ponto de propondo estudos que pensem as organizações em quanto formas estruturais em constante elaboração social.

Acreditamos serem necessários outros estudos com o propósito de compreender mais profundamente as questões peculiares levantadas por este trabalho, os quais muito provavelmente demandarão conhecimentos além do campo da administrativo, como por exemplo, o campo do conhecimento da história, da teologia etc., para melhor compreensão da realidade organizacional. Ademais, destacamos que neste estudo, por questões de viabilidade da pesquisa, limitamos a analisar apenas o líder paroquial (na figura do padre) e a linha subjacente da organização (os coordenadores de pastorais, movimentos e secretária). Sendo assim, como uma limitação da pesquisa a ser superada, a importância de se desenvolver pesquisas que amplie o escopo de análise nos mais variados níveis organizacionais.

\title{
Referências
}

Cardim, P. (2001) Religião e Ordem Social. Revista de História das Ideias: O Estado e a Igreja. Impactum Coimbra University Press, v. 22, 133-174.

Compêndio Pastoral Fé e Política. (2005). Compêndio da doutrina social da igreja. São Paulo: Edições Paulinas.

Conferência Nacional dos Bispos do Brasil. (2008). Projeto Nacional de Evangelização: O Brasil na Missão Continental. Brasília, Edições CNBB.

Gil, A. C. (2002). Como elaborar projeto de pesquisa. São Paulo: Atlas.

Godoi, C. K.; Mattos, P. L. C. L. (2010). Entrevista qualitativa: instrumento de pesquisa e evento dialógico. In SILVA, A, B.; GODOI, C. K.; MELLO, R. B. (Org.), Pesquisa qualitativa em estudos organizacionais: paradigmas, estratégias e métodos (cap. 10). São Paulo: Saraiva, 2010.

Gonçalves, j. C. S.; serra, a. R. C.; costa, C. E. S. (2007). A empresarização do sagrado: um estudo sobre a estruturação de igrejas protestantes brasileiras. Revista Eletrônica de Ciência Administrativa, 6(2), 1-14.

Lima, A. S. (2016).Gestão de pessoas em organizações religiosas: o caso da Igreja Presbiteriana do Brasil (Dissertação de Mestrado). Universidade Presbiteriana Mackenzie, São Paulo, SP, Brasil.

Maximiano, A. (2010). Introdução à Administração. São Paulo: Atlas.

Merriam, S. B. (2009). Qualitative Research: A guide to design and interpretation. San Francisco: JosseyBass.

Mintzberg, H. (1981). Organization design: fashion or fi t? Harvard Business Review. jan/feb, 103-116.

Mintzberg, H. (2003). Criando organizações eficazes. São Paulo: Atlas.

Nicolini, D. (2013). Practice Theory, Work, \& Organization: an introduction. Oxford: Oxford University Press.

Schultz, G. (2016). Introdução à gestão de organizações. Porto Alegre: Editora da UFRGS.

Serafim, M. C.; Alperstedt, G. D. (2012). As organizações religiosas e suas relações: Uma análise a partir da teoria dos stakeholders. Revista de Negócios, v. 17 (2), 21-40.

Sobral, F. (2008). Administração: Teoria e prática no contexto brasileiro. São Paulo: Pearson Prentice Hall. Stoner, J. (1999). Administração. Rio de Janeiro: Prentice Hall do Brasil.

Woods Jr., T. E. (2008). Como a Igreja Católica construiu a civilização ocidental. São Paulo: Quadrante.

\section{A Religious Organization analyzed through the Theory of Organizational Structure in Mintzberg}

\begin{abstract}
In this study our objective was to relate the theory of organizational structure in Mintzberg $(1981,2003)$ to a religious organization. Once these organizations have peculiar characteristics while its institutionalization in the social, politic and cultural ambit in the communities where they work on, organized trough the volunteer work, solidarity and dogmatic beliefs. Thereby, to understand the organizational structure and your characteristics, a qualitative research was made, using interviews with several organizational leaderships, including the main leader in the organization. We realized an organizational structure which focus in the "mechanized bureaucracy", which is composed of three different organizational parts, managed mainly through mutual adjustments.
\end{abstract}

Keywords: Organizational Structure, Catholic Church, Mintzberg. 


\section{Una Organización Religiosa pensada a partir de laTeoría de lasEstructuras Organizativas enMintzberg}

\section{Resumen}

En este estudio objetivo fue pensar la teoría de las estructuras organizacionales en Mintzberg $(1981,2003)$ a partir de una organización religiosa. Una vez que estas organizaciones presentan características peculiares mientras su institucionalización en el ámbito social, político y cultural en las comunidades en que se hacen presentes, organizadas a través del trabajo voluntario, solidaridad y creencias dogmáticas. Así, para comprender la estructura organizativa y sus características, se realizó una investigación cualitativa, a través de entrevistas con diversos liderazgos organizacionales, incluida figura del líder principal de la organización. Logramos percibir una estructura organizacional con foco en la burocracia mecanizada, compuesta por tres partes organizativas distintas coordinadas principalmente por medio del ajuste mutuo.

Palabras Clave: Estructura Organizacional, Iglesia Católica, Mintzberg.

\section{Sobre os Autores}

\section{Bertha Maria do Amaral e SILVA}

Graduanda em Administração pela Universidade Federal de Pernambuco (UFPE)

Rodovia BR-104, Km 59, s/n - Nova Caruaru - Caruaru - PE - Brasil - CEP 55002-970.

E-mail: bertha.amaral@hotmail.com

\section{Ítalo Henrique de Freitas Ramos da SILVA}

Graduando em Administração pela Universidade Federal de Pernambuco (UFPE)

Rodovia BR-104, Km 59, s/n - Nova Caruaru - Caruaru - PE - Brasil - CEP 55002-970.

E-mail: italohenriquedefreitas@gmail.com

\section{Bruno Gustavo Ferreira do NASCIMENTO}

Graduando em Administração pela Universidade Federal de Pernambuco (UFPE)

Rodovia BR-104, Km 59, s/n - Nova Caruaru - Caruaru - PE - Brasil - CEP 55002-970.

E-mail: bruno-gustavo75@hotmail.com

\section{Elisabeth Cavalcante dos SANTOS}

Professora Adjunta do Núcleo de Gestão do Centro Acadêmico do Agreste da Universidade Federal de Pernambuco (CAA/UFPE). Pesquisadora do Grupo de Estudos e Intervenções do Agreste (GEIA). Doutora em Administração pelo Programa de Pós Graduação em Administração da Universidade Federal da Paraíba (UFPB).

Rodovia BR-104, Km 59, s/n - Nova Caruaru - Caruaru - PE - Brasil - CEP 55002-970.

E-mail: elisabethcsantos@gmail.com 